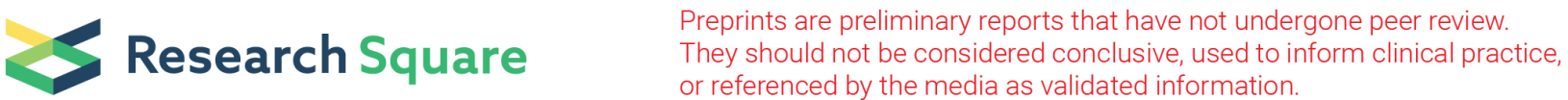 \\ Validation of the Nutrient-Rich Foods Index Estimated by 24-hour Dietary Recall Method in Chinese Mid-Eastern Adults
}

Junya Zhai ( $\sim$ zhaijunya1229@126.com )

Affiliated Tumor Hospital of Zhengzhou University: Henan Cancer Hospital https://orcid.org/00000001-6195-3321

\section{Baihui Ma}

Affiliated Tumor Hospital of Zhengzhou University: Henan Cancer Hospital

\section{Quanjun LYU}

Zhengzhou University First Affiliated Hospital

\section{Lijun Guo}

Affiliated Tumor Hospital of Zhengzhou University: Henan Cancer Hospital

\section{Pipasha Khatun}

Zhengzhou University

\section{Minghua Cong}

Cancer Hospital Chinese Academy of Medical Sciences

\section{Yongxia Kong}

Affiliated Tumor Hospital of Zhengzhou University: Henan Cancer Hospital

Rui Liang

Zhengzhou University First Affiliated Hospital

\section{Research}

Keywords: Nutrient-Rich, Dietary Recall

Posted Date: April 20th, 2021

DOl: https://doi.org/10.21203/rs.3.rs-418610/v1

License: (c) (i) This work is licensed under a Creative Commons Attribution 4.0 International License. Read Full License 


\section{Abstract}

Objectives

The Nutrient-Rich Foods (NRF) Index is an important nutrient profiling model. Nutrition quality indices need to be tested and validated against the quality of the total diet and against health outcomes. $A$ family of NRF indices was validated against the mean adequacy ratio (MAR), an overall measure of the nutrient adequacy. Besides, we examined the associations between the NRF index and obesity indicators.

Methods

A total of 656 persons aged 18-75 years from Henan province of China since 2020 were studied. All foods consumed by participants were scored using NRFn.2 (where $n=6-11$ ) indices based on unweighted sums, means, and ratios of percent Chinese Dietary Reference Intakes (DRIs) for beneficial nutrients ( $n$ ) and nutrients to limit (2). NRF index scores in this study were calculated on $100 \mathrm{~g}, 100 \mathrm{kcal}$ basis. The measure of index performance was the percentage of adjusted variation in MAR $\left(R^{2}\right)$. Multi-factor logistic regression models were used to examine the association between the NRF index scores and obesity indicators.

Results

The NRF9. 2 index, based on 9 beneficial nutrients and 2 nutrients to limit, using the algorithm based on sums and $100 \mathrm{kcal}$, was the best predicted model, with an adjusted $\mathrm{R}^{2}$ of 0.23 by multiple adjustments. The odds ratio (OR) for overweight (defined by BMI) in the 4th quartile (Q4) versus the 1st quartile (Q1) of the NRF9. 2 index was $0.61(95 \% \mathrm{Cl}=0.37,0.98)$ after multiple adjustments. However, the NRF9.2 index score was not related to central obesity.

Conclusion

NRF9. 2 index, using the algorithm based on sums and $100 \mathrm{kcal}$, was the best predicted model. NRF9.2 index scores were associated with BMI. These results revealed that the NRF9.2 index can be used as a validated tool to assess the overall diet quality among mid-eastern Chinese adults.

\section{Introduction}

An estimated 41 million people worldwide died of chronic non-communicable diseases (NCDs) in 2016, equivalent to $71 \%$ of all deaths ${ }^{[1]}$. The underlying causes of the main NCDs include genetic predispositions, modifiable risk behaviors (such as tobacco use, harmful use of alcohol, physical inactivity and unhealthy diets) and environmental risks. Dietary risks were responsible for 7.94 million deaths and 188 million disability-adjusted life years globally among adults in $2019^{[2]}$. Thus, suggestions on dietary improvements should be imperative. 
Despite the amount of knowledge on the benefits of a nutritionally balanced to prevent NCDs, the prevalence of these diseases has been increasing. More and more researchers found that NCDs are associated with a high intake of energy-dense, nutrient-poor (EDNP) foods. Consuming EDNP foods may increase the risk of high energy intake, marginal micro-nutrient intake and low serum concentrations of vitamins ${ }^{[3]}$. Such unbalanced diets are modifiable risk factors for the development of obesity ${ }^{[4]}$, nonalcoholic fatty liver disease ${ }^{[5]}$, metabolic syndrome ${ }^{[6]}$, bone health ${ }^{[7]}$ and so on. Moreover, the Dietary Guidelines for Americans (DGA) since 2005 state that Americans should consume a variety of nutrientdense foods and beverages within and among the basic food groups. Thus, more attention was paid to nutrient profiling (NP) models, which are intended to capture the nutrient density of food ${ }^{[8,9]}$. NP aims to rank foods based on their nutrient content as opposed to their energy content ${ }^{[10]}$. The Nutrient Rich Foods (NRF) Index is a crucial NP model, which takes a great quantity of beneficial nutrients and a great quantity of nutrients to limit into account. Each food is assigned a unique NRF score that reflects its total nutritional value per reference amount. Not limited to individual foods only, the NRF algorithm can be applied to food groups, meals, menus, and total diets ${ }^{[11]}$. A family of nutrient-rich foods (NRF) indices has been validated against the Healthy Eating Index $(\mathrm{HEI})^{[12]}$ and the Dutch Healthy Diet Index ${ }^{[13]}$. Diets with high NRF index score protect against central obesity ${ }^{[14]}$, higher body mass index $(\mathrm{BMI})^{[15]}$ and was inversely associated with all-cause mortality ${ }^{[16]}$. The NRF index is a valid measure of diet quality in some countries.

China has achieved remarkable economic progress in recent years. Accompanied by these rapid economic changes, diet is undergoing an alarming transition: more fat and meat are consumed; EDNP foods intakes are increasing ${ }^{[17]}$. The validity of the NRF index has not yet been established in Chinese adults. Also, Drewnowski ${ }^{[11]}$ proposed that the chosen models must be validated against independent measures of a healthy diet and, ideally, against health outcomes. Based on the reasons above, the objective of this study was to test several NRF indices scores for measures of a healthy diet among Chinese Mid-Eastern adults, based on Chinese Dietary Reference Intakes (DRIs) ${ }^{[18]}$ and using mean adequacy ratio (MAR), an overall measure of the nutrient adequacy ${ }^{[19]}$. Percent of variation in MAR explained (adjusted $\mathrm{R}^{2}$ ) was the key criterion of index performance. The indices that best predicted variation in MAR were then further characterized by calculating scores on a food group basis. We also aimed to explore the relationship between the NRF index and obesity indicators using obesity as an entry point to provide a reasonable and healthy diet for the prevention of NCDs, thereby reducing the incidence of NCDs caused by dietary factors.

\section{Subjects And Methods}

\subsection{Study design and population}

Participants for this analysis were from the cross-sectional study, which aimed to collect information on the diet, life style, and anthropometry of adults (aged 25-75 years) in 3 study sites (2 physical examination centers and 1 community) in Henan province of China since 2020. In total, 912 individuals 
were invited, of which 785 agreed to participate. Individuals with incomplete data (missing data on 24-h dietary recalls $(n=26)$, on anthropometry $(n=28)$, on covariate $(n=28))$ and implausible energy intake $(n=47)^{[20]}$ were excluded. Written informed consent was obtained from all subjects.

\subsection{Dietary and covariant assessment}

Data were collected by a general questionnaire and through two non-consecutive $24-\mathrm{h}$ dietary recalls. To help the respondents answer accurately, 24-h dietary recalls were investigated face to face with the aid of food models. The average daily intakes of various foods and nutrients were analyzed by nutrition calculator (NCCW software), which was calculated based on the China Food Composition Tables [21]. Weight, height, waist circumference (WC) and hip circumference $(\mathrm{HC})$ were measured by experienced investigators. The general questionnaire assessed age, gender, educational attainment, occupational status, smoking status, grip, family number, snap, sedentary time, physical activity, and so on.

\subsection{Nutrient-rich food index scores evaluated}

NRF index scores were based upon several nutrient profile models previously investigated by Drewnowski et al. ${ }^{[22]}$. The number of beneficial nutrients has ranged from 5 to 20 whereas the number of unhealthy nutrients has ranged from zero to 4 . Considering the limitation of the Chinese food composition table ${ }^{[18]}$, this study only included 11 encourage nutrients (protein, dietary fibre, vitamin $A, C, E, B{ }_{12}, \mathrm{Ca}, \mathrm{Fe}, \mathrm{Mg}, \mathrm{K}$, $\mathrm{Zn}$ ) and 2 limited nutrients (saturated fat, Na). Thus, only NRF6.2, NRF9.2 and NRF 11.2 indice were adopted in this study.

Three different bases of calculation were used in the NRF model: $100 \mathrm{~g}, 100 \mathrm{kcal}$, and serving size ${ }^{[11]}$. The concept of serving size is rarely used in the unit of measurement of food in China. Thus, NRF index scores in this study were calculated per $100 \mathrm{~g}$, per $100 \mathrm{kcal}$ of food. The daily reference intakes of nutrients were based on the recommended nutrient intake (RNI) or adequate intake (Al) of adults except for saturated fat, which was based on acceptable macro-nutrient distribution ranges (Table 1$)^{[18]}$. The algorithms used to calculate the NRF index scores evaluated are listed in Table $2^{[23]}$.

\subsection{Assessment of nutrient adequacy}

Nutrient adequacy was measured by computing MAR. To compute MAR first nutrient adequacy ratio (NAR) was calculated for the selected 10 nutrients as given in Table 3. NAR was calculated based on DRIs. MAR was calculated as described by Madden et al ${ }^{[19]}$.

\section{$\mathrm{NAR}=\frac{\text { Actual nutrient intake of a nutrient (per day) }}{\text { Chinese daily reference intakes of the nutrient }}$ MAR $=\frac{\sum \text { NAR }(\text { each truncated at } 1)}{\text { Number of nutrients }}$}




\subsection{Assessment of basic characteristics}

Anthropometric measurements were performed by trained investigators using standardized procedures. Body weight (nearest $0.1 \mathrm{~kg}$ ) and height (nearest $0.1 \mathrm{~cm}$ ) were measured in duplicate by using an ultrasonic weight and height instrument while the participants were barefoot and wearing light clothes only. BMI was calculated in the standard way: weight $(\mathrm{kg})$ divided by square of height $(\mathrm{m})$, which was classified as underweight $\left(<18.5 \mathrm{~kg} / \mathrm{m}^{2}\right)$, normal weight $\left(\geq 18.5\right.$ and $\left.<23.9 \mathrm{~kg} / \mathrm{m}^{2}\right)$, overweight $(\geq 24$ and $<27.9 \mathrm{~kg} / \mathrm{m}^{2}$ ) and obese ( $\geq 28 \mathrm{~kg} / \mathrm{m}^{2}$ ) according to the Working Group on Obesity in China (WGOC) ${ }^{[24]}$.

Waist and hip circumferences were measured to the nearest $0.1 \mathrm{~cm}$ using a flexible metric measuring tape with the individual in a standing position. WC was measured around the abdomen at the level of the umbilicus. The hip circumference is the maximum circumference of the hip. Central obesity was defined by WC and Waist-to-hip ratio (WHR). The cut-off point of WC was recommended by WGOC: $85 \mathrm{~cm}$ for males and $80 \mathrm{~cm}$ for females ${ }^{[24]}$. WHR was calculated as WC $(\mathrm{cm})$ divided by $\mathrm{HC}(\mathrm{cm})$. There is no standard for judging the cut-off point of WHR in China. Central obesity was defined according to the WHO recommendation: WHR $\geq 0.90$ for males, and WHR $\geq 0.85$ for females ${ }^{[25]}$.

Physical activity was collected through the Chinese version of the international physical activity questionnaire (IPAQ) ${ }^{[26]}$, which appeared to have acceptable reliability and validity. The moderatevigorous physical activity (MET-h/d, MET, metabolic equivalent of task) was calculated for each individual according to Chinese Guidelines for Chinese Residents ${ }^{[27]}$.

\subsection{Quality control}

Quality control was carried out from questionnaire design to data analysis: Firstly, the questionnaire used in the investigation was revised after pilot study and expert discussion. Secondly, all investigators must undergo unified training before the interview. Last but not the least, all data were inputted by two persons, and logical error detection and review were carried out.

\subsection{Statistical analysis}

Data analysis was done by using SAS statistical software, version 9.3 (SAS Institute, Cary, NC, USA), for all data analyses. A $p$-value $<0.05$ was considered statistically significant.

The distribution of variables was calculated and compared according to categories of NRF9.2 score based on the Kruskal-Wallis test for continuous variables. Multiple linear regression models were used to analyze the correlation between NRF index score and MAR. The NRF index was selected according to the adjusted $\mathrm{R}^{2}$. Potential confounders that were considered include: age, gender, smoking (yes or not), life pressure (yes or not), grip strength (normal or not), sedentary time (h/day), family number. The NRF index score in quartiles (Q1-Q4) was taken as the independent variable and the dependent variable was overweight (including obesity) or central obesity. In the basic models (model 1), the correlation analyses between the NRF index score and overweight/central obesity were carried out first by crude odds ratios 
(OR) with 95\% confidence interval (Cl); Model 2 was adjusted for age (continuous), gender and educational level $(<6,6 \sim 12,>12$ years). Model 3 was further adjusted for personal monthly income (<2000, 2000 5000, >5000 RMB), moderate-vigorous activity (Low / relatively low / relatively high / high) and nap frequency (continuous).

\section{Results}

3.1 Validation. All NRF indices were positively correlated $(P<0.001)$ with MAR (Figures 1 and 2$)$, with adjusted $R^{2}$ ranging from 0.114 to 0.232 by adjusted for age, gender, $B M I$, smoking, life pressure, grip strength, sedentary time and family number. NRF9.2 index using the algorithm based on sums and 100 kcal had the highest $R^{2}(0.232)$.

3.2 General characteristics of the distribution of NRF9.2 index scores. Because the NRF9.2 index using the algorithm based on sums and $100 \mathrm{kcal}$ had the best ability to predict MAR, we then scored all foods consumed by participants. The mean NRF9.2 Index score of the participants was $39.93(32.44,47.84)$. We explore the distribution of NRF9.2 Index score among gender, age, central obesity (defined by WC and WHR), overweight (defined by BMI), residence, personal monthly income, educational level, occupation, marriage and family number (Table 4). The diet quality of females (NRF9.2 Index score 41.37 (33.53, $50.73)$ ) was higher than that of males (NRF9.2 Index score $38.83(31.83,46.25))$. The diet quality of an individual with high education (NRF9.2 Index score $43.33(36.30,51.78)$ ) was higher than that of a person with low education (NRF9.2 Index score $38.26(32.37,45.42)$ ).

3.3 Means of food groups and selected nutrients across quartiles of the NRF 9.2 index score. Significant and positive correlations of the NRF9.2 Index score with the majority of food groups except for meat, poultry and fish (Table 5). We also found that the higher the NRF9.2 index score, the higher intake of advantage nutrients. However, the intake of selenium, zinc, phosphorous was not significantly associated with the NRF9.2 index score (Table 6).

3.4 The association between the NRF9.2 index scores and overweight, central obesity. The odds ratio (OR) for overweight (defined by BMI) in the 4th quartile (Q4) versus the 1st quartile (Q1) of the NRF9.2 index was $0.61(95 \% \mathrm{Cl}=0.37,0.98)$ after multiple adjustments. However, the NRF9.2 index score was not related to central obesity, whether it was defined based on WC or WHR(Table 7).

\section{Discussion}

The NRF index has been proposed to predict overall diet quality in Americans, Dutch and Japanese, while it has not yet been evaluated in Chinese. In this study in Mid-Eastern Chinese adults, we observed that the optimal NRF indices was the NRF9.2 index, which is composed of nine nutrients to encourage and two nutrients to limit, using the algorithm based on sums and $100 \mathrm{kcal}$. The NRF9.2 index score was found to be related not only to the foods/food groups, but also to other essential nutrients not incorporated into the NRF9.2 index, such as thiamine, riboflavin, nicotinic acid, phosphorus, and zinc. NRF9.2 index was 
inversely associated with overweight (BMI, WGOC), but not with central obesity after adjustment for potential confounders. These results revealed that the NRF9.2 index can be used as a validated tool to assess the overall diet quality among Mid-Eastern Chinese adults.

Choosing the best NRF index among multiple alternatives is a scientific challenge. Of the fifteen tested scores, the prediction of the MAR was highest for the NRF9.2, with an $R^{2}$ of 0.23 . In the previous study, the NRF9.3 index based on $100 \mathrm{kcal}$ best predicted the HEI-2005 with an $\mathrm{R}^{2}$ of $0.45^{[12]}$ and the DHD-index with an $\mathrm{R}^{2}$ of $0.34^{[13]}$. Compared with the above researches, the proportion of explained variance of the NRF index scores against the MAR was somewhat lower, but not to a great extent. This might be caused by the different daily reference intakes of nutrients, different study populations, differences between MAR and the HEI, the DHD-index or different nutrients included in the NRF index. Considering the less readily available added sugars data and the relatively low consumption level of added sugar in China ${ }^{[28]}$, the total sugar or added sugar is not incorporated into the NRF indices. In addition, this study confirmed previous studies ${ }^{[22]}$ showing that increasing the number of nutrients above 10 in a nutrient profile model provided little or no additional benefit in predicting overall diet quality. This choice was mainly based on Americans, whereas other nutrients might be more important for certain specific health outcomes or the Chinese. Nevertheless, the prediction of the MAR did not differ to a great extent between the scores and NRF index performed best in the Chinese population as well as in the US and Dutch population, a nutrient profile model for specific nationality from other parts of China and for a special purpose is expected. Regarding reference bases, serving size was rarely used in the unit of measurement of food in China, which was not adopted in the present study. Algorithms per $100 \mathrm{kcal}$, best reflected the original concept of nutrient density of foods, had higher $\mathrm{R}^{2}$ values than those based on 100 gram which make no allowances for the fact that different foods and beverages are consumed in very different amounts ${ }^{[11]}$. The preferred algorithms were those that were based on sums, rather than a mean or ratio between the positive and negative nutrients. Compared with algorithms based on mean or ratio, those based on sums appear to be simplest, more transparent and weigh all nutrients equally [29].

In this study, the participants with higher the NRF9.2 scores had lower intakes of cereals and snacks, while with higher intakes of vegetables, fruits, beans and eggs; In terms of nutrient, the higher NRF9.2 scores, the higher intakes of vitamin $B_{1}$, vitamin $B_{2}$ and vitamin $P P$, the lower intakes of energy, carbohydrate and fat. Therefore, the NRF9.2 index can be used as one of the effective tools to evaluate dietary quality from the point of view, as it is consistent with the key recommendations of dietary guidelines for Chinese residents ${ }^{[27]}$. Socioeconomic factors correlated with the NRF9.2 Index were identified. Female and an individual had a higher level of education had better diet quality, which is consistent with the existing dietary indices ${ }^{[30]}$. It possibly because they have increasing nutrition knowledge ${ }^{[31]}$, which was an indicator of the ability to translate nutrition knowledge into better dietary practices.

At present, multiple efforts to explore the relationship of nutrient profile models and various measures of anthropometry are underway. It is, however, not yet clear whether the NRF index is helpful in weight 
management. A study on 2,696 adults from the United States and the United Kingdom ${ }^{[32]}$ showed that the NRF index was negatively related to BMI, consistent with our findings. While a sample of 4969 , aged $>55$ years was carried out in the Netherlands found that the NRF9.3 index score was positively associated with $\mathrm{BMI}^{[33]}$, which possibly related to underreporting of food intake in the obese subject. In terms of central obesity, Streppel et al. found that the NRF9.3 index score was positively associated with WC and waist-to-height ratio ${ }^{[33]}$. The inconsistency in the relationship of NRF9.3 and obesity indicators may be related to the following factors: (1) The characteristics of the subjects are different, including race, age, gender and health status. (2) The cut-off of obesity was quite different. (3)The method of statistical analysis is different, as some studies just explore the crude correlation, while others adjusted the possible confounding factors. (4) Some nutrients included in the NRF9.2 index were slightly different, for example added sugar was adopted in the NRF9.2 index in Aljuraiban's study ${ }^{[32]}$, while total sugar was adopted in Streppel ${ }^{[33]}$ and both were abandoned in this study. Thus, the association between the NRF9.2 and obesity is therefore complex.

The present study has its limitations. Firstly, our study has a cross-sectional design, which failed to determine the exact causality of NRF9.2 index and weight gain and should be interpreted cautiously. However, we plan to conduct a follow up study to explore the cause-effect relationship. Secondly, the finding is only applicable to the mid-east Chinese, as China has a vast territory and abundant resources, and there are great cultural differences among different ethnic groups. More research needs to be carried out in different regions and ethnic groups. However, we plan to conduct multi center research to Increase the representativeness of the sample. The other limitation of this research is that it does not take into account the other beneficial nutrients or other non- nutrient substances like phytochemicals, which may be essential for the Chinese. Finally, the sample used in our analysis is not as large as that used in other cross-sectional studies. However, our analysis excluded any energy under-reporters and was carefully adjusted with potential confounders.

\section{Conclusion}

To our knowledge, we are the first who studied the validation of the NRF index in Chinese Mid-Eastern adults. Our findings demonstrated that the NRF9.2 index, using the algorithm based on sums and 100 kcal, was the best predicted model, with highly associated with MAR. NRF9.2 index scores were associated with BMI. These results revealed that the NRF9.2 index can be used as a validated tool to assess the overall diet quality among Chinese adults. Modifying food-selected behavior through consuming a nutrient-dense diet may be an important approach to control epidemic obesity.

\section{Declarations}

\section{Acknowledgements}

We thank the participants for their willingness to participate in this study. Our special thanks go to Yafei Sun and Xiumei Xu for their assisting with collection and input of the data. 


\section{Funding}

This work was supported by the Chinese Nutrition Society (CNS) Nutrition Science Foundation-Sino Nutrifood Oligopeptide Nutrition Research Fund (CNS-FF2019A26).

\section{Author contributions}

All authors had full access to all of the data and take responsibility for the integrity of the data and the accuracy of the data analysis. Baihui Ma, Lijun Guo, Yongxia Kong acquired the data. Junya Zhai, Baihui Ma and Rui Liang analyzed and interpreted the data. Junya Zhai, Baihui Ma drafted the manuscript, which was critically revised for important intellectual content by all authors. Quanjun LYU and Minghua Cong were responsible for the statistical analysis and revised the manuscript. Junya Zhai supervised the study and is a guarantor.

\section{Availability of data and materials}

The datasets used and/or analyzed during the current study available from the corresponding author on reasonable request.

\section{Ethics approval and consent to participate}

The Committee on Human Subjects at The first affiliated hospital of Zhengzhou University approved the study design (Protocol 2020-KY-066). All subjects have signed a consent form to participate of the study.

\section{Consent for publication}

Not applicable.

\section{Competing interests}

The authors declare that they have no competing interests.

\section{Authorship}

${ }^{1}$ Department of Clinical nutrition, Affiliated Cancer Hospital of Zhengzhou University, Henan Cancer Hospital, Zhengzhou, China. ${ }^{2}$ Department of Clinical nutrition, The first affiliated Hospital of Zhengzhou University, Zhengzhou, China. ${ }^{3}$ Department of Nutrition and Food Hygiene, College of Public Health, Zhengzhou University, Zhengzhou, Henan, China. ${ }^{4}$ Department of Comprehensive Oncology, National Cancer Center/National Clinical Research Center for Cancer/Cancer Hospital, Chinese Academy of Medical Sciences.

\section{References}


[1] Global health estimates 2016: deaths by cause a, sex, by country and by region, 2000-2016. Geneva, World Health Organization; 2018 (https://www.who.int/healthinfo/global_burden_disease/estimates/en/, accessed 20 April 2020). [J].

[2] Global burden of disease cause and risk summaries. Risk factors. . Dietary Risks. Vol. 396. (2020).Available online at: https://www.thelancet.com/pb-assets/Lancet/gbd/summaries/risks/dietaryrisks.pdf

[3] Kant AK. Consumption of energy-dense, nutrient-poor foods by adult americans: Nutritional and health implications. The third national health and nutrition examination survey, 1988-1994 [J]. Am J Clin Nutr, 2000,72(4):929-936.

[4] Kant AK, Graubard BI. Energy density of diets reported by american adults: Association with food group intake, nutrient intake, and body weight [J]. Int J Obes (Lond), 2005,29(8):950-956.

[5] Yari Z, Cheraghpour M, Aghamohammadi V, et al. Energy-dense nutrient-poor snacks and risk of nonalcoholic fattyliver disease: A case-control study in iran [J]. BMC Res Notes, 2020,13(1):221.

[6] Mirmiran P, Bahadoran Z, Delshad H, et al. Effects of energy-dense nutrient-poor snacks on the incidence of metabolic syndrome: A prospective approach in tehran lipid and glucose study [J]. Nutrition, 2014,30(5):538-543.

[7] McNaughton SA, Wattanapenpaiboon N, Wark JD, et al. An energy-dense, nutrient-poor dietary pattern is inversely associated with bone health in women [J]. J Nutr, 2011,141(8):1516-1523.

[8] Drewnowski A. Concept of a nutritious food: Toward a nutrient density score [J]. Am J Clin Nutr, 2005,82(4):721-732.

[9] Drewnowski A, Fulgoni V, 3rd. Nutrient profiling of foods: Creating a nutrient-rich food index [J]. Nutr Rev, 2008,66(1):23-39.

[10] Drewnowski A, Fulgoni VL, Young MK, et al. Nutrient-rich foods: Applying nutrient navigation systems to improve public health [J]. J Food Sci, 2008,73(9):H222-228.

[11] Drewnowski A. Defining nutrient density: Development and validation of the nutrient rich foods index [J]. J Am Coll Nutr, 2009,28(4):421S-426S.

[12] Fulgoni VL, 3rd, Keast DR, Drewnowski A. Development and validation of the nutrient-rich foods index: A tool to measure nutritional quality of foods [J]. J Nutr, 2009,139(8):1549-1554.

[13] Sluik D, Streppel MT, van Lee $L$, et al. Evaluation of a nutrient-rich food index score in the netherlands [J]. J Nutr Sci, 2015,4(e14):1-9. 
[14] Zaki M, Hussein L, Gouda M, et al. Nutritional epidemiological study to estimate usual intake and to define optimum nutrient profiling choice in the diet of egyptian youths [J]. Food and Nutrition ences, 2015,06(15):1422-1436.

[15] Nansel TR, Haynie DL, Lipsky LM, et al. Multiple indicators of poor diet quality in children and adolescents with type 1 diabetes are associated with higher body mass index percentile but not glycemic control [J]. Journal of the Academy of Nutrition \& Dietetics, 2012,112(11):1728-1735.

[16] Davies, Sue. Nutrient-rich foods, cardiovascular disease and all-cause mortality: The rotterdam study [J]. Primary Health Care, 2015,25(1):741-747.

[17] Zhai F, Wang H, Du S, et al. Prospective study on nutrition transition in china [J]. Nutr Rev, 2009,67 (Suppl 1):S56-61.

[18] Nutrition CSo. Chinese dietary reference intakes (2013) [M]. Beijing,China: Science Press, 2014.

[19] Madden JP, Goodman SJ, Guthrie HA. Validity of the 24-hr. Recall. Analysis of data obtained from elderly subjects [J]. Journal of the American Dietetic Association, 1976,68(2):143-147.

[20] Huang TT, Roberts SB, Howarth NC, et al. Effect of screening out implausible energy intake reports on relationships between diet and bmi [J]. Obes Res, 2005,13(7):1205-1217.

[21] YuexinYang. China food composition tables [M]. 2019.

[22] Drewnowski A, Maillot M, Darmon N. Testing nutrient profile models in relation to energy density and energy cost [J]. Eur J Clin Nutr, 2009,63(5):674-683.

[23] Drewnowski A, Fulgoni VL, 3rd. Nutrient density: Principles and evaluation tools [J]. Am J Clin Nutr, 2014,99(5 Suppl):1223S-1228S.

[24] Zhou B. [predictive values of body mass index and waist circumference to risk factors of related diseases in chinese adult population] [J]. Zhonghua Liu Xing Bing Xue Za Zhi, 2002,23(1):5-10.

[25] He M, Tan KC, Li ET, et al. Body fat determination by dual energy x-ray absorptiometry and its relation to body mass index and waist circumference in hong kong chinese [J]. Int $\mathrm{J}$ Obes Relat Metab Disord, 2001,25(5):748-752.

[26] Qu NN, Li KJ. [study on the reliability and validity of international physical activity questionnaire (chinese vision, ipaq)] [J]. Zhonghua Liu Xing Bing Xue Za Zhi, 2004,25(3):265-268.

[27] Society CN. Dietary guidelines for chinese residents(2016) [M]. Beijing: People's Medical Publishing House, 2016.

[28] Liu S, Yu D, Guo Q, et al. [consumption status and trend of added sugar containing food among chinese from 2002 to 2012] [J]. Wei Sheng Yan Jiu, 2016,45(3):398-401. 
[29] Tetens I, Oberdörfer R, Madsen C, et al. Nutritional characterisation of foods: Science-based approach to nutrient profiling. Summary report of an ilsi europe workshop held in april 2006 [J]. Eur J Nutr, 2007,46(Suppl 2):4-14.

[30] Hiza HA, Casavale KO, Guenther PM, et al. Diet quality of americans differs by age, sex, race/ethnicity, income, and education level [J]. J Acad Nutr Diet, 2013,113(2):297-306.

[31] Yahia N, Brown CA, Rapley M, et al. Level of nutrition knowledge and its association with fat consumption among college students [J]. BMC Public Health, 2016,16(1):1047.

[32] Aljuraiban GS, Chan Q, Griep LMO, et al. The impact of eating frequency and time of intake on nutrient quality and body mass index: The intermap study, a population-based study [J]. Journal of the American Academy of Nutrition \& Dietetics, 2015,115(4):528-536.

[33] Streppel MT, de Groot LC, Feskens EJ. Nutrient-rich foods in relation to various measures of anthropometry [J]. Fam Pract, 2012,29(Suppl 1):i36-43.

\section{Tables}

Table 1 Chinese Dietary Reference Intakes based on age and gender for calculating NRF index 


\begin{tabular}{|c|c|c|c|c|c|c|}
\hline \multirow[t]{2}{*}{ Nutrients } & \multicolumn{3}{|l|}{ male } & \multicolumn{3}{|c|}{ female } \\
\hline & $18-$ & $50-$ & $65-$ & $18-$ & $50-$ & $65-$ \\
\hline Energy (kcal) & 2250 & 2100 & 2050 & 1800 & 1750 & 1700 \\
\hline Potein & 65 & 65 & 65 & 55 & 55 & 55 \\
\hline Dietary fiber ( $g$ & 25 & 25 & 25 & 25 & 25 & 25 \\
\hline Vitamin A ( $\mu \mathrm{gRE} \rrbracket$ & 800 & 800 & 800 & 700 & 700 & 700 \\
\hline Vitamin $\mathrm{C} \rrbracket \mathrm{mg} \mathbb{\nabla}$ & 100 & 100 & 100 & 100 & 100 & 100 \\
\hline Vitamin E『mg a-TE\ & 14 & 14 & 14 & 14 & 14 & 14 \\
\hline Calcium $₫ \mathrm{mg} \rrbracket$ & 800 & 1000 & 1000 & 800 & 1000 & 1000 \\
\hline Iron $\rrbracket \mathrm{mg} \rrbracket$ & 9 & 9 & 9 & 15 & 9 & 9 \\
\hline Potassium $₫ \mathrm{mg} \rrbracket$ & 2000 & 2000 & 2000 & 2000 & 2000 & 2000 \\
\hline Magnesium $₫ \mathrm{mg} \rrbracket$ & 330 & 330 & 320 & 330 & 330 & 320 \\
\hline Zinc $₫ \mathrm{mg} \rrbracket$ & 12.5 & 12.5 & 12.5 & 7.5 & 7.5 & 7.5 \\
\hline Vitamin $B_{12} \llbracket \mu g \square$ & 2.4 & 2.4 & 2.4 & 2.4 & 2.4 & 2.4 \\
\hline Saturated fat $₫ \mathrm{~g} \rrbracket$ & 25 & 23.3 & 22.8 & 20 & 19.4 & 18.9 \\
\hline Sodium $\nabla \mathrm{mg} \rrbracket$ & 1500 & 1400 & 1400 & 1500 & 1400 & 1400 \\
\hline
\end{tabular}

Table 2 Algorithms for the NRF Index Score 


\begin{tabular}{|c|c|c|c|}
\hline Model & Algorithm & $\begin{array}{l}\text { Reference } \\
\text { Amount }\end{array}$ & Comment \\
\hline \multicolumn{4}{|l|}{$\mathrm{NRn}^{1}$} \\
\hline NRn_100g & $\begin{aligned} \sum_{1-n}\left(\text { Nutrient }_{i}\right. & \\
& \left./ N V R_{i}\right) \\
& \times 100\end{aligned}$ & $100 \mathrm{~g}$ & $\begin{array}{l}\text { Nutrient: content of nutrient } \mathrm{i} \text { in } \\
100 \text {-kcal edible portion } \mathrm{NRV}_{\mathrm{i}}= \\
\text { Nutrient } \mathrm{t}_{\mathrm{i}} \text { based on Chinese } \\
\text { Dietary Reference Intakes }\end{array}$ \\
\hline NRn_100 kcal & $\left(N R n_{-} 100 \mathrm{~g} / \mathrm{ED}\right) \times 100$ & $100 \mathrm{kcal}$ & ED:energy density (kcal/100 g) \\
\hline LIM $^{2}$ & & & Include saturated fat and sodium \\
\hline LIM_100 g & $\begin{aligned} \sum_{1-3}\left(L_{i} / M\right. & \\
& \times 100\end{aligned}$ & $100 \mathrm{~g}$ & $\begin{array}{l}L_{i} \text { : content of limiting nutrient } \mathrm{i} \\
\text { in } 100-\mathrm{kcal} \text { edible portion; } \\
\mathrm{MNRV}_{i} \text { :maximum xdaily } \\
\text { values for nutrient i }\end{array}$ \\
\hline $\begin{array}{l}\text { LIM_100 kcal } \\
\text { NRFn.3 }\end{array}$ & $($ LIM_100 g/ED) $\times 100$ & NRFn.3 & ED: energy density (kcal/100 g) \\
\hline NRFn.3_sum_100 g & NRn_100 g- LIM_100 g & $100 \mathrm{~g}$ & \\
\hline $\begin{array}{c}\text { NRFn.3_sum_100 } \\
\text { kcal }\end{array}$ & $\begin{array}{l}\text { NRn_100kcal- LIM_100 } \\
\mathrm{kcal}\end{array}$ & $100 \mathrm{kcal}$ & Difference between sums \\
\hline NRFn.3_mean_100 g & NRn/n_100g-LIM_100g & $100 \mathrm{~g}$ & \\
\hline $\begin{array}{c}\text { NRFn.3_mean_100 } \\
\text { kcal }\end{array}$ & $\begin{array}{l}\text { NRn/n_100kcal- } \\
\text { LIM_100 kcal }\end{array}$ & $100 \mathrm{kcal}$ & Difference between means \\
\hline NRFn.3_ratio & $\mathrm{NRn} / \mathrm{LIM}$ & None & $\begin{array}{l}\text { NRn_100 g/LIM_100 g= } \\
\text { NRn_100kcal/LIM_100kcal }\end{array}$ \\
\hline
\end{tabular}

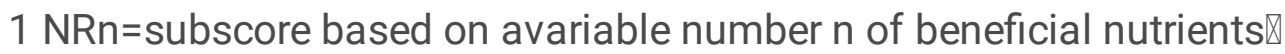

2 LIM=Limited nutrient score『

Table 3 Chinese Dietary Reference Intakes based on age and gender for calculating MAR 


\begin{tabular}{|c|c|c|c|c|c|c|}
\hline \multirow[t]{2}{*}{ Nutrients } & \multicolumn{3}{|l|}{ male } & \multicolumn{3}{|c|}{ female } \\
\hline & $18-$ & $50-$ & $65-$ & $18-$ & $50-$ & $65-$ \\
\hline Energy(kcal) & 2250 & 2100 & 2050 & 1800 & 1750 & 1700 \\
\hline protein(g) & 65 & 65 & 65 & 55 & 55 & 55 \\
\hline 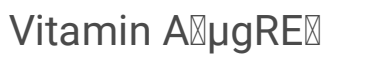 & 800 & 800 & 800 & 700 & 700 & 700 \\
\hline Vitamin C邓mg $\triangle$ & 100 & 100 & 100 & 100 & 100 & 100 \\
\hline calcium $\rrbracket \mathrm{mg} \rrbracket$ & 800 & 1000 & 1000 & 800 & 1000 & 1000 \\
\hline Iron $\rrbracket \mathrm{mg} \rrbracket$ & 9 & 9 & 9 & 15 & 9 & 9 \\
\hline Phosphorous $₫ \mathrm{mg} \rrbracket$ & 2000 & 2000 & 2000 & 2000 & 2000 & 2000 \\
\hline Vitamin B1】mg】 & 1.4 & 1.4 & 1.4 & 1.2 & 1.2 & 1.2 \\
\hline Vitamin B2】mg》 & 1.4 & 1.4 & 1.4 & 1.2 & 1.2 & 1.2 \\
\hline Vitamin PP『mgNE】 & 15 & 14 & 14 & 12 & 12 & 11 \\
\hline
\end{tabular}

Table 4 General characteristics of the distribution of NRF9.2 scores 


\begin{tabular}{|c|c|c|c|}
\hline Vairable & $\mathrm{n}$ & The score of NRF9. $2^{1}$ & $P$ value ${ }^{2}$ \\
\hline Total & 656 & $39.93 \llbracket 32.44,47.84 \rrbracket$ & - \\
\hline \multicolumn{4}{|l|}{ Gender } \\
\hline Male & 396 & $38.83(31.83,46.25)$ & \multirow[t]{2}{*}{0.004} \\
\hline Female & 260 & $41.37(33.53,50.72)$ & \\
\hline \multicolumn{4}{|l|}{ Age } \\
\hline$<50$ & 99 & $38.42(29.85,47.78)$ & \multirow[t]{3}{*}{0.350} \\
\hline $50-65$ & 407 & $39.91(32.49,48.10)$ & \\
\hline$>65$ & 150 & $41.04(34.19,47.04)$ & \\
\hline \multicolumn{4}{|l|}{ Central obesity(WC) } \\
\hline Yes & 290 & $39.88(32.60,47.96)$ & 0.6 \\
\hline No & 366 & $40.04(31.71,47.33)$ & \\
\hline \multicolumn{4}{|l|}{ Central obesity(WHR) } \\
\hline Yes & 298 & $39.68(32.62,47.92)$ & 0.9 \\
\hline No & 358 & $40.49(31.62,47.87)$ & \\
\hline Overweight(BMI, WGOC! & & & 0.7 \\
\hline Yes & 285 & $39.90(32.75,48.16)$ & \\
\hline No & 371 & $40.30(31.97,48.16)$ & \\
\hline Residation & & & 0.067 \\
\hline Urban & 559 & $40.43(32.58,48.06)$ & \\
\hline Village & 97 & $37.32(31.55,44.03)$ & \\
\hline Personal monthly income & & & 0.199 \\
\hline$<2000 \mathrm{RMB}$ & 152 & $38.26(32.37,45.42)$ & \\
\hline 2000 5000 RMB & 399 & $39.91(31.74,48.20)$ & \\
\hline$>5000 \mathrm{RMB}$ & 105 & $41.77(33.62,48.99)$ & \\
\hline Educational level & & & $<0.0001$ \\
\hline$<6$ years & 80 & $38.42(37.76,55.66)$ & \\
\hline $6 \sim 12$ years & 424 & $38.51(31.38,45.39)$ & \\
\hline$>12$ years & 152 & $43.33(36.30,51.78)$ & \\
\hline
\end{tabular}




\begin{tabular}{|lccl|}
\hline Vairable & $\mathrm{n}$ & The score of NRF9.2 $^{1}$ & $P_{\text {value }}{ }^{2}$ \\
\hline Occupation & & & 0.13 \\
\hline Manual & 98 & $37.43(31.69,45.33)$ & \\
\hline Professional & 82 & $41.61(33.45,49.58)$ & \\
\hline Retired & 332 & $40.23(33.11,48.09)$ & \\
\hline Others & 144 & $39.03(30.92,47.21)$ & \\
\hline Marriage & & & 0.84 \\
\hline Yes & 601 & $39.94(32.46,47.82)$ & \\
\hline Others & 55 & $39.16(32.29,49.53)$ & \\
\hline Family number & & & 0.27 \\
\hline$\leq 4$ & 422 & $39.16(31.97,47.50)$ & \\
\hline 44 & 234 & $41.00(32.49,48.13)$ & \\
\hline
\end{tabular}

1. Values are presented as median (25th percentile, 75th percentile).

2. The general characteristics of the distribution of NRF9.2 scores was tested by Kruskal-Wallis $\square$

Table 5 Means of food groups intake across quartiles of the NRF 9.2 index score ${ }^{1}$ 


\begin{tabular}{|c|c|c|c|c|c|}
\hline \multirow[t]{2}{*}{ Food group } & \multicolumn{4}{|c|}{ NRF9.2 index score 2} & \multirow[t]{2}{*}{$P \square^{3}$} \\
\hline & Q1 & Q2 & Q3 & Q4 & \\
\hline $\mathrm{n}$ & 143 & 144 & 144 & 144 & \\
\hline $\begin{array}{l}\text { NRF9.2 index } \\
\text { score }\end{array}$ & $\begin{array}{l}22.04(26.43 \\
31.62)\end{array}$ & $\begin{array}{l}36.62(34.79 \\
38.09)\end{array}$ & $\begin{array}{l}43.28(41.72 \\
45.18)\end{array}$ & $\begin{array}{l}54.69(50.74 \\
59.57)\end{array}$ & $<0.0001$ \\
\hline Grains & $\begin{array}{l}463.25(318.20 \\
619.13)\end{array}$ & $\begin{array}{l}409.25(296.88 \\
520.00)\end{array}$ & $\begin{array}{l}373.90(271.63 \\
490.60)\end{array}$ & $\begin{array}{l}304.75(230.00 \\
416.35)\end{array}$ & $<0.0001$ \\
\hline Vegetables & $\begin{array}{l}\text { 75.00(32.13, } \\
129.80)\end{array}$ & $\begin{array}{l}\text { 128.00(67.55, } \\
204.93)\end{array}$ & $\begin{array}{l}\text { 166.50(92.88, } \\
249.75)\end{array}$ & $\begin{array}{l}208.50(102.75 \\
298.90)\end{array}$ & $<0.0001$ \\
\hline Fruits & $0(0,172.00)$ & $3.5(0,230.00)$ & $\begin{array}{l}\text { 115.00(0, } \\
299.55)\end{array}$ & $\begin{array}{l}250.55(101.85 \\
500.00)\end{array}$ & $<0.0001$ \\
\hline $\begin{array}{l}\text { Milk and milk } \\
\text { products }\end{array}$ & $0(0,0)$ & $0(0,0)$ & $0(0,0)$ & $0(0,9.38)$ & 0.006 \\
\hline $\begin{array}{l}\text { Beans, nuts, } \\
\text { and seeds }\end{array}$ & $0(0,5)$ & $0(0,12.63)$ & $0(0,28.00)$ & $4.5(0,29.70)$ & $<0.0001$ \\
\hline $\begin{array}{l}\text { Meat, poulty } \\
\text { and fish }\end{array}$ & $\begin{array}{l}23.60(0.00 \\
67.15)\end{array}$ & $\begin{array}{l}25.00(0.00 \\
68.75)\end{array}$ & $\begin{array}{l}25.00(0.00 \\
66.87)\end{array}$ & $\begin{array}{l}28.50(0.00 \\
82.78)\end{array}$ & 0.29 \\
\hline egg & $20(0,60)$ & $30(0,60.00)$ & $41(0,66.00)$ & $60(0,70.23)$ & 0.004 \\
\hline Snacks ${ }^{4}$ & $\begin{array}{l}8.00(2.00 \\
66.00)\end{array}$ & $\begin{array}{l}5.00(2.93 \\
11.90)\end{array}$ & $5.00(3.00,9.00)$ & $4.3(2.8,8.18)$ & 0.057 \\
\hline
\end{tabular}

1. Values are presented as median (25th percentile, 75th percentile).

2. Q1, 1st quartile; Q2, 2nd quartile; Q3, 3rd quartile; Q4, 4th quartile.

3. The differences of food groups intake among quartiles of the NRF 9.2 index score were tested by Kruskal-Wallis test.

4. Snacks includes cookies, fast food, sugar preserved fruits and so on!

Table 6 Means of nutrients intake across quartiles of the NRF 9.2 index score ${ }^{4}$ 


\begin{tabular}{|c|c|c|c|c|c|}
\hline \multirow{2}{*}{$\begin{array}{l}\text { Energy } \\
\text { and nutrients }\end{array}$} & \multicolumn{4}{|c|}{ NRF9. 2 index score ${ }^{1}$} & \multirow[t]{2}{*}{$P \square^{3}$} \\
\hline & Q1 & Q2 & Q3 & Q4 & \\
\hline $\mathrm{n}$ & 164 & 164 & 164 & 164 & \\
\hline Energy $₫$ kcal $\mathbb{}$ & $\begin{array}{l}1560(1257, \\
2021)\end{array}$ & $1470(1211,1794)$ & $\begin{array}{l}\text { 1380(1144, } \\
1811)\end{array}$ & $\begin{array}{l}1384(1143 \\
1662)\end{array}$ & 0.001 \\
\hline Fat $₫ g \rrbracket$ & $\begin{array}{l}39.25(28.68 \\
60.48)\end{array}$ & $\begin{array}{l}35.15(24.25 \\
50.55)\end{array}$ & $\begin{array}{l}34.10(23.92, \\
46.14)\end{array}$ & $\begin{array}{l}36.00(25.58 \\
44.90)\end{array}$ & 0.008 \\
\hline $\begin{array}{l}\text { Carbohydrate } \\
\mathbb{\nabla g} \rrbracket\end{array}$ & $\begin{array}{l}240.39 \\
(193.38 \\
305.66)\end{array}$ & $\begin{array}{l}245.67(195.97 \\
286.11)\end{array}$ & $\begin{array}{l}230.91 \\
(175.54 \\
287.14)\end{array}$ & $\begin{array}{l}215.52 \\
(170.47 \\
265.60)\end{array}$ & 0.002 \\
\hline $\begin{array}{l}\text { Vitamin B1 } \\
\bigotimes \text { mg } \rrbracket\end{array}$ & $\begin{array}{l}0.63(0.45 \\
0.88)\end{array}$ & $0.75(0.51,0.97)$ & $\begin{array}{l}0.75(0.57 \\
0.96)\end{array}$ & $\begin{array}{l}0.77(0.56 \\
0.97)\end{array}$ & 0.018 \\
\hline $\begin{array}{l}\text { Vitamin B2 } \\
\text { 『mg } \rrbracket\end{array}$ & $\begin{array}{l}0.56(0.41 \\
0.74)\end{array}$ & $0.58(0.46,0.75)$ & $\begin{array}{l}0.64(0.47 \\
0.83)\end{array}$ & $\begin{array}{l}0.72(0.54, \\
0.91)\end{array}$ & $<0.0001$ \\
\hline $\begin{array}{l}\text { Vitamin PP } \\
\text { 『mg } \rrbracket\end{array}$ & $\begin{array}{l}8.46(5.49 \\
12.12)\end{array}$ & $8.96(6.10,12.51)$ & $\begin{array}{l}8.42(6.17 \\
11.88)\end{array}$ & $\begin{array}{l}9.73(7.14 \\
13.20)\end{array}$ & 0.04 \\
\hline $\begin{array}{l}\text { Phosphorous } \\
\text { \mg } \\
end{array}$ & $\begin{array}{l}702.55 \\
(556.48 \\
891.28)\end{array}$ & $\begin{array}{l}728.29(606.54 \\
937.15)\end{array}$ & $\begin{array}{l}764.80 \\
(623.57 \\
955.27)\end{array}$ & $\begin{array}{l}791.61 \\
(612.51 \\
958.30)\end{array}$ & 0.06 \\
\hline Zinc $\ m g \rrbracket$ & $\begin{array}{l}6.76(5.36 \\
8.46)\end{array}$ & $7.26(5.89,8.94)$ & $\begin{array}{l}7.06(5.74 \\
9.11)\end{array}$ & $\begin{array}{l}7.69(6.07, \\
9.51)\end{array}$ & 0.095 \\
\hline $\begin{array}{l}\text { Selenium } \\
\bigotimes \mathrm{mg} \rrbracket\end{array}$ & $\begin{array}{l}34.88(25.03 \\
49.95)\end{array}$ & $38.48(28.33,50.81)$ & $\begin{array}{l}38.96(27.30 \\
51.46)\end{array}$ & $\begin{array}{l}35.24(26.10 \\
50.43)\end{array}$ & 0.6 \\
\hline MAR & $\begin{array}{l}0.53(0.44 \\
0.63)\end{array}$ & $\begin{array}{l}57.76(48.45, \\
66.17)\end{array}$ & $\begin{array}{l}61.90(52.11 \\
69.77)\end{array}$ & $\begin{array}{l}67.25(57.40 \\
77.03)\end{array}$ & $<0.0001$ \\
\hline
\end{tabular}

1. Values are presented as median (25th percentile, 75th percentile).

2. Q1, 1st quartile; Q2, 2nd quartile; Q3, 3rd quartile; Q4, 4th quartile.

3. The differences of food groups intake among quartiles of the NRF 9.2 index score were tested by Kruskal-Wallis test.

4. Table 9 listed the nutrients incorporated into the NRF9.2 index.

Table 7 The association between the NRF9.2 index scores and obesity indicators 


\begin{tabular}{|c|c|c|c|c|c|}
\hline & & \multicolumn{4}{|c|}{ NRF9. 2 index score ${ }^{1}$} \\
\hline & & Q1 & Q2 & Q3 & Q4 \\
\hline \multirow[t]{3}{*}{ 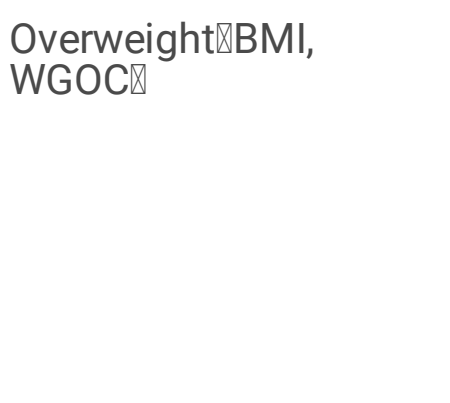 } & $\begin{array}{l}\text { Model } \\
1^{2}\end{array}$ & 1.00 & $\begin{array}{l}0.85(0.54 \\
1.33)\end{array}$ & $\begin{array}{l}1.12(0.72 \\
1.74)\end{array}$ & $\begin{array}{l}0.85(0.54 \\
1.33)\end{array}$ \\
\hline & $\begin{array}{l}\text { Model } \\
2^{3}\end{array}$ & 1.00 & $\begin{array}{l}0.87(0.55 \\
1.37)\end{array}$ & $\begin{array}{l}1.04(0.66 \\
1.65)\end{array}$ & $\begin{array}{l}0.73(0.46 \\
1.17)\end{array}$ \\
\hline & $\begin{array}{l}\text { Model } \\
3^{4}\end{array}$ & 1.00 & $0.76(0.47,1.22)$ & $0.92(0.57,1.48)$ & $0.61(0.37,0.98)$ \\
\hline \multirow[t]{3}{*}{ Central obesity $₫ W C \otimes^{2}$} & $\begin{array}{l}\text { Model } \\
1^{2}\end{array}$ & 1.00 & $\begin{array}{l}0.85(0.52 \\
1.40)\end{array}$ & $\begin{array}{l}1.01(0.62 \\
1.65)\end{array}$ & $0.85(0.52,1.65)$ \\
\hline & $\begin{array}{l}\text { Model } \\
2^{3}\end{array}$ & 1.00 & $\begin{array}{l}0.85(0.52 \\
1.40)\end{array}$ & $\begin{array}{l}0.97(0.59 \\
1.59)\end{array}$ & $\begin{array}{l}0.83(0.50 \\
1.37)\end{array}$ \\
\hline & $\begin{array}{l}\text { Model } \\
3^{4}\end{array}$ & 1.00 & $\begin{array}{l}0.72(0.43 \\
1.22)\end{array}$ & $\begin{array}{l}0.94(0.56 \\
1.57)\end{array}$ & $0.78(0.46,1.33)$ \\
\hline \multirow[t]{3}{*}{ Central obesity $₫ \mathrm{WHR} \rrbracket^{2}$} & $\begin{array}{l}\text { Model } \\
1^{2}\end{array}$ & 1.00 & $\begin{array}{l}0.72(0.41 \\
1.26)\end{array}$ & $\begin{array}{l}1.05(0.62, \\
1.79)\end{array}$ & $\begin{array}{l}0.93(0.54 \\
1.59)\end{array}$ \\
\hline & $\begin{array}{l}\text { Model } \\
2^{3}\end{array}$ & 1.00 & $\begin{array}{l}0.70(0.39 \\
1.25)\end{array}$ & $\begin{array}{l}1.03(0.59 \\
1.79)\end{array}$ & $\begin{array}{l}0.93(0.54 \\
1.59)\end{array}$ \\
\hline & $\begin{array}{l}\text { Model } \\
3^{4}\end{array}$ & 1.00 & $\begin{array}{l}0.60(0.32 \\
1.08)\end{array}$ & $\begin{array}{l}0.93(0.52 \\
1.65)\end{array}$ & $\begin{array}{l}0.97(0.54 \\
1.74)\end{array}$ \\
\hline
\end{tabular}

1. Values are presented as $\mathrm{OR}(95 \%$ confidence interval).

2. Crude model[

3. Model 2 was adjusted for age (continuous), gender and educational level $(<6,6 \sim 12,>12$ years) were adjusted.

4. Model 3 was further adjusted for personal monthly income (<2000, 2000 5000, >5000 RMB), moderate-vigorous activity (Low / relatively low / high / high) and nap frequency (continuous).

\section{Figures}




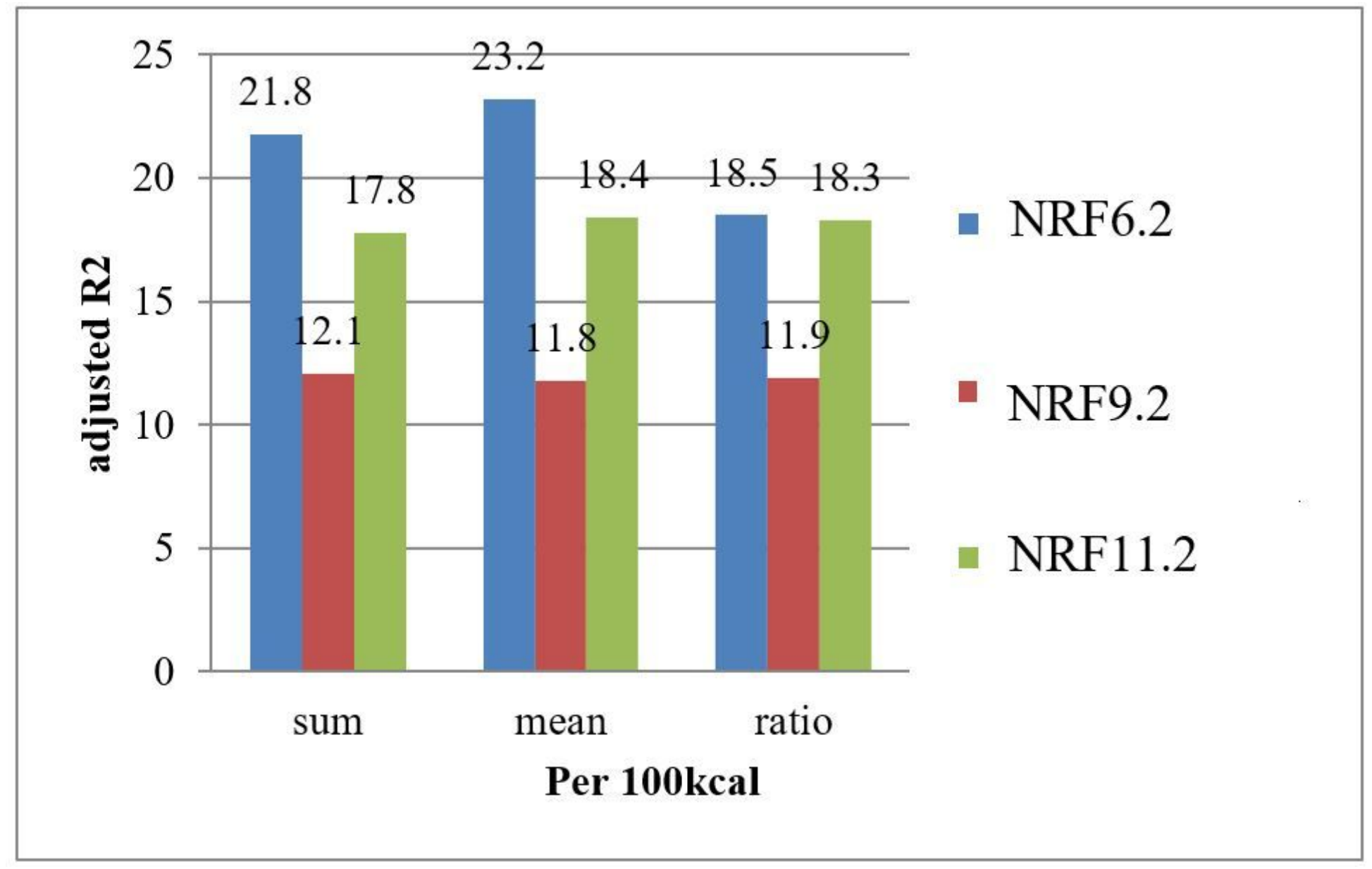

Figure 1

R2 comparison of NRFn.2 algorithms calculated per $100 \mathrm{kcal}$ from regression models predicting MAR

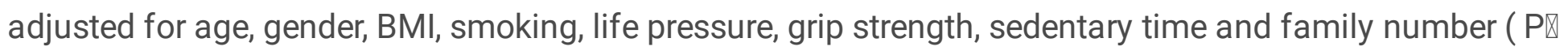
0.0001). NRF6.2 refers the 6 encourage nutrients (protein, dietary fibre, vitamin A, C, Ca, Fe,) and 2 limit nutrients (saturated fat, Na). NRF9.2 is NRF6.2 plus vitamin E, magnesium, and potassium; NRF11.2 is NRF9.2 plus vitamin B-12 and zinc. 


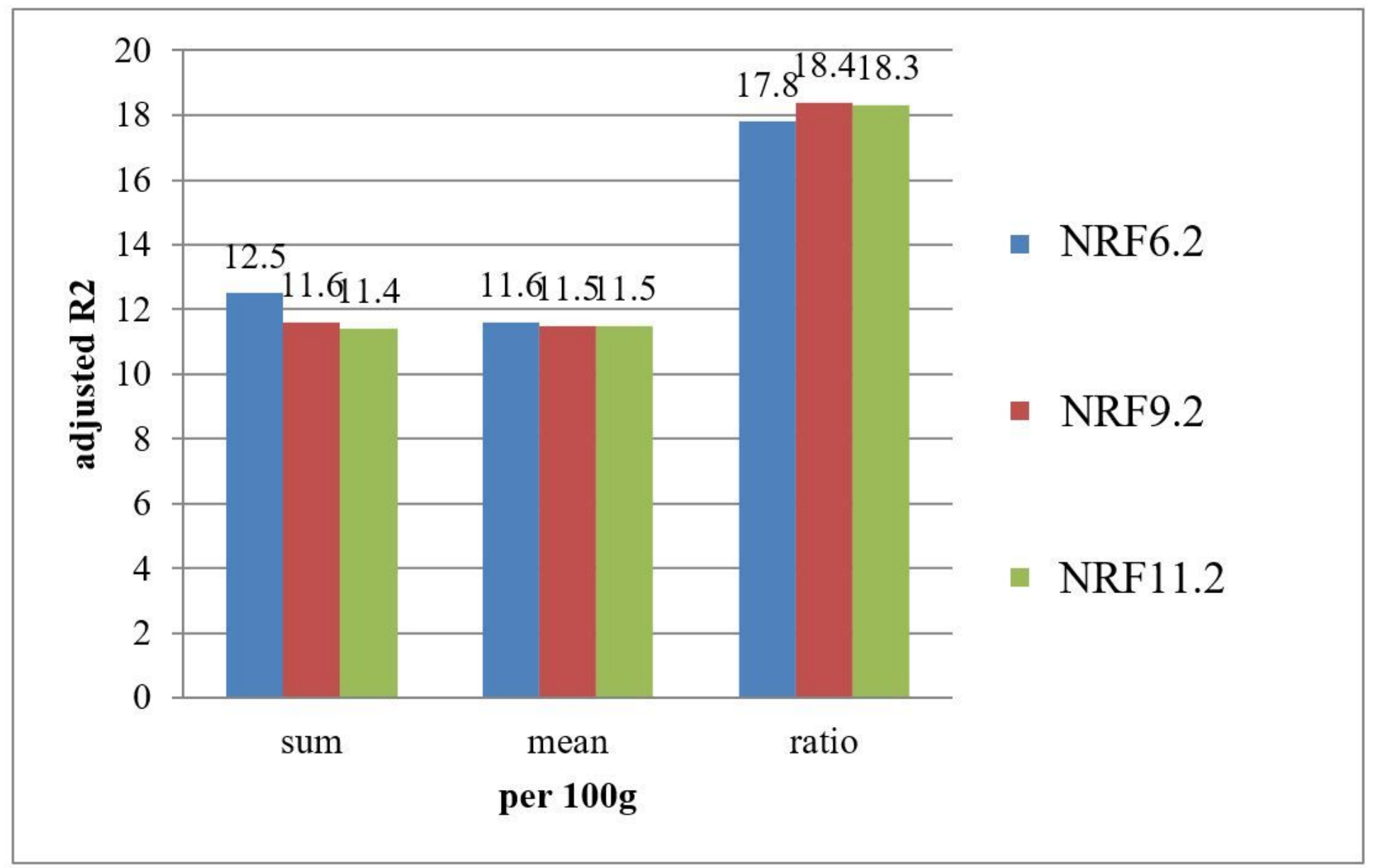

\section{Figure 2}

R2 comparison of NRFn.2 algorithms calculated per 100 gram from regression models predicting MAR

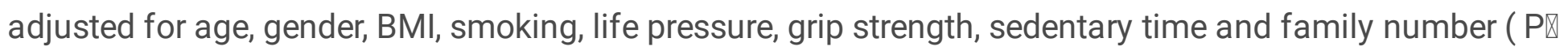
0.0001). NRF6.2 refers the 6 encourage nutrients (protein, dietary fibre, vitamin A, C, Ca, Fe, ) and 2 limit nutrients (saturated fat, Na). NRF9.2 is NRF6.2 plus vitamin E, magnesium, and potassium; NRF11.2 is NRF9.2 plus vitamin B12 and zinc. 